\title{
Trends and Patterns of Educational Homogamy in India: A Marriage Cohort Analysis
}

\author{
Kakoli Borkotoky ${ }^{1}$ and Ashish Kumar Gupta ${ }^{2}$ \\ ${ }^{1}$ Population Council, 142 Golf Links, New Delhi 110003, India \\ ${ }^{2}$ Population Council, India Habitat Centre, Core 5A, Ground Floor, Lodhi Road, New Delhi 110003, India \\ Correspondence should be addressed to Kakoli Borkotoky; kakoli.26nov@gmail.com
}

Received 16 April 2016; Revised 10 July 2016; Accepted 28 July 2016

Academic Editor: Shirlena Huang

Copyright ( $2016 \mathrm{~K}$. Borkotoky and A. K. Gupta. This is an open access article distributed under the Creative Commons Attribution License, which permits unrestricted use, distribution, and reproduction in any medium, provided the original work is properly cited.

\begin{abstract}
Research in assortative mating in developing countries focused mainly on the cultural similarities of individuals till the most recent times. Educational homogamy was not considered a significant factor. This study examined the changes in educational homogamy of 39,257 ever-married couples in India for the three marriage cohorts 1964-1984, 1985-1995, and 1996-2006 by place of residence, religion, and economic background. The study also examined the regional pattern of educational homogamy based on female literacy and the probability of educational homogamy after adjusting for socioeconomic background of the respondent. Data from the National Family Health Survey (NFHS-3) was used for the study. The study observed significant increase in educational homogamy for the successive marriage cohorts. Homogamy is concentrated at the extremes of the educational attainment. In urban areas, homogamy is concentrated among the higher educated individuals whereas, in rural areas, homogamy is high among uneducated individuals. The results also depict regions with higher female literacy having the highest educational homogamy and vice versa. The study also found an increase in the probability of homogamy and a decline in hypogamy for literate women, after accounting for socioeconomic confounders.
\end{abstract}

\section{Background}

Assortative mating has for long received considerable worldwide attention from researchers of family studies and demography. In earlier times, marriages between individuals with similar characteristics such as origin, religion, social status, and education make up the predominant pattern [1]. Of late, there has been growing interest in analysing the trends and patterns of educational assortative mating in developed as well as developing countries [2,3]. Another study [4] agreed upon the transformations in Asian marriage systems under the impact of increase in literacy level, urbanization, and employment. There is no dearth of studies on educational homogamy in developed countries, but the significance of educational attainment in mate selection remains relatively less explored in developing nations, particularly in India. With improvement in overall literacy, the role of education in mate selection is expected to undergo significant changes in India as well. It is rightly pointed out by a recent study that, in order to highlight the changes in marriage patterns in Asia, it is equally important to examine who marries whom in terms of age, education, and other attributes in addition to timing of entry into marriage [5]. The study therefore examined educational homogamy in India for specific marriage cohorts on the assumption that socioeconomic changes in the country will have a distinct effect on an entire cohort and, hence, it will be easy to differentiate cohorts from one another.

Becker [6-8] suggested that mate selection can be either positive or negative. Positive selection occurs when traits complement each other; selection is negative if the traits are substitute to one another. It was also documented that mate selection depends on individual preferences, influence of the social group, and constraints of the marriage market in which people interact [1]. In recent times, there has been an increase in likelihood of marriages among people of similar educational attainment, especially at the two extremes $[2,3]$. In an important contribution to the research on marriage and fertility in India, the researcher mentioned that 
increase in education of women increases the likelihood of finding marriage partner with same/higher/desired level of educational attainment [9]. Several studies have emphasised that educational assortative mating has significant bearing on socioeconomic condition of the household and intergenerational transmission of social behaviour [1,10-17]. Some other studies suggest that educational homogamy may also increase social inequity $[2,8,12,15,18]$.

In developed countries, women have equal say in choosing their marriage partner, which is stimulated by their education levels and greater participation in the labor force. In such societies, individual choices on mate selection are more important than parental preferences. In contrast, marriages in developing countries are heavily influenced by race, religion, and household wealth. Like many other developing countries, marriages in India also used to be a predominantly familyinfluenced affair that was mainly guided by cultural practices [19]. Mate selection was primarily the responsibility of the parents. Similarities of ethnicity, religion, and socioeconomic status were the chief considerations in the selection of a mate [20, 21]. Additionally, age at marriage for both men and women is low and there is a wide age gap in couples in developing countries.

However, a few recent studies showed that pattern of marriage is undergoing changes across the globe, and developing countries are also no exception $[18,22,23]$. Besides social and cultural similarities, individual attributes like intelligence and education emerged as a significant factor of mate selection. Therefore, changes in the marriage patterns cannot be examined in isolation from improvements in the levels of education [24]. Female literacy rate in India increased from around 9 percent in 1951 to 66 percent in 2011. Increase in the education levels empowers women to make decisions about employment, marriage, and family formation. With higher educational attainment, expectations, aspirations, and choices will be expectedly different for better educated women from their less educated counterparts. Educated women will prefer to marry someone with equal level of education.

The factors associated with marriage pattern need to be studied in greater depth, especially in the Indian context where the social dynamics of marriage and mate selection are undergoing dramatic changes. Indians from different backgrounds follow traditions that are specific to their culture. Consequently, marriage and kinship structures also vary according to race, ethnicity, religion, and region of residence. In Northern India, marriage is allowed only between nonrelatives. On the other hand, consanguineous marriages are common in many parts of South India. Therefore, all such variations in culture and social beliefs are reflected in the mate selection process in India. Any study of the patterns of educational homogamy in India must necessarily examine the various dimensions of its immense diversity.

Studies of marriage and family formations in India have also reported increase in the mean age at marriage, intercaste marriages, and decline in the age gap between husband and wife $[25,26]$. Although these studies examined the changes in the pattern of marriages in India, there still exists large gaps in our understanding of educational homogamy and more so from a nationally representative perspective. Within the theoretical framework enunciated in extant literature, the study seeks to address the following questions: what is the pattern of change in educational homogamy in India and is the pattern the same for people with different socioeconomic background? Essentially thus, the aim of this study is to examine the changes in educational homogamy in the background of improvement in the levels of literacy in the country.

\section{Data and Methods}

The study used data from the third National Family Health Survey (NFHS-3, 2005-06), which is the Indian equivalent of the Demographic and Health Survey (DHS). In NFHS-3, information was collected from a nationally representative sample of 109041 households; 124385 women aged 15-49 and 74369 men aged 15-54 were interviewed. The present study analysed data collected from 39257 ever-married couples in the age group of 15-49 years who were staying together during the survey period. NFHS-3 provided information on age and year of marriage, details on the educational attainments of the couples, and other socioeconomic characteristics.

The sample was divided into three marriage cohorts: 1964-84, 1985-95, and 1996-2006. First, the study attempted to use four marriage cohorts; due to small sample size in the first two cohorts (1964-73, 1974-84) we combined the first two cohorts and limit the analysis to three marriage cohorts. The study examined the pattern of homogamy, hypergamy, and hypogamy in terms of educational attainment of couples. Educational attainment was divided into four categories: no education, primary (up to 4 years of schooling), secondary (up to 10 years of schooling), and higher education $\left(10^{+}\right.$ years of schooling). The classifications for education used in this paper are taken directly as given in the survey. The study also examined the pattern of educational homogamy by place of residence (rural, urban), religion (Hindu, Muslim, Christian, and others), caste (scheduled caste, scheduled tribe, other backward classes, and others), wealth quintile (poorest, poorer, middle, richer, and richest), and geographic regions (North, Central, East, Northeast, West, and South). In the present study, homogamy is defined as marriage of individuals with similar educational attainment. Hypergamy is when husband has higher education than wife, and hypogamy is where husband has lower education than the wife.

The main focus of the study is to examine the changes in marriage patterns in India based on educational attainment. Educational attainment of men and women were categorised as follows: no education, primary, secondary, and higher. Since educational categories were ordered from lowest to highest, ordered logistic regression was applied to estimate the probability of marriage between men and women with different levels of education. The research hypothesis to be tested is educational attainment is not associated with the probability of partner selection for marriage. The main advantage of using ordered logistic regression is that it gives the probability of homogamy, hypergamy, and hypogamy for each level of educational attainment. The results show the predicted probabilities instead of odds ratio because it is easier to interpret the probability of marrying men from 
TABLE 1: Classification of states into different geographic regions of India according to NFHS-3 criteria.

\begin{tabular}{ll}
\hline Region & States \\
\hline North & Delhi, Haryana, Himachal Pradesh, Jammu and \\
Kashmir, Punjab, Rajasthan, Uttaranchal \\
Central & Chhattisgarh, Madhya Pradesh, Uttar Pradesh \\
East & Bihar, Jharkhand, Orissa, West Bengal \\
Northeast & $\begin{array}{l}\text { Arunachal Pradesh, Assam, Manipur, Meghalaya, } \\
\text { Mizoram, Nagaland, Sikkim, Tripura }\end{array}$ \\
West & Goa, Gujarat, Maharashtra \\
South & Andhra Pradesh, Karnataka, Kerala, Tamil Nadu \\
\hline
\end{tabular}

each category of education than interpreting the odds for each educational category. Education of husband was the dependent variable and education of women and other background characteristics were taken as independent variable in the ordered logistic regression. In the first model, the probabilities were calculated using educational attainments of husband as the dependent variable and education of wife as the single independent variable (unadjusted probabilities). In the next model, year of marriage, wealth index, religion, caste, and place of residence were added as independent variables to estimate the probabilities (adjusted). The states were grouped into six geographical regions based on the classification used in NFHS-3 (Table 1).

\section{Results}

3.1. Changes in Educational Attainment over Marriage Cohorts. The distribution of educational attainment is presented in Table 3. The proportion of women with a primary education and above increased from 46 percent in 1964-84 cohort to 75 percent in the 1996-2006 cohort. Similarly, the proportion of women with secondary education and higher also increased from 28 percent in 1964-84 to 62 percent in the 1996-2006 cohort. The educational attainment of men also improved in this period. The proportion of men with primary education and above increased from 72 percent in 1964-84 to 85 percent in the 1996-2006 cohorts. Also, the percentage of men with secondary education and above increased from 52 in 1964-84 to 72 in the 1996-2006 marriage cohorts. Descriptive statistics for the variables used in the study are given in Table 2.

\subsection{Educational Homogamy across Marriage Cohorts in India.} The patterns of educational attainment of the couples in rural and urban areas in the three marriage cohorts are given in Table 4. Educational homogamy in urban areas increased from 49.7 percent (1964-84) to 55.4 percent (1985-95) and 62.7 percent (1996-2006). In the rural areas homogamy increased from 50 percent (1964-84) to 52.6 percent (19962006). In rural areas, percentage share in total homogamy is high for the illiterate ( 34 percent out of 50 percent) in the first marriage cohort. In the third marriage cohort, homogamy is high for the high educated ( 29 percent out of 53 percent) in the rural areas. In urban areas, homogamy is high among the
TABLE 2: Descriptive statistics for the variables used in the analysis.

\begin{tabular}{|c|c|c|}
\hline & Percent & Sample size \\
\hline \multicolumn{3}{|l|}{ Marriage cohort } \\
\hline 1964-1984 & 20.9 & 8205 \\
\hline 1985-1995 & 39.1 & 15368 \\
\hline 1996-2006 & 40.0 & 15684 \\
\hline \multicolumn{3}{|l|}{ Place of residence } \\
\hline Urban & 47.0 & 18442 \\
\hline Rural & 53.0 & 20815 \\
\hline \multicolumn{3}{|l|}{ Education of husband } \\
\hline No education & 21.3 & 8359 \\
\hline Primary & 15.5 & 6072 \\
\hline Secondary & 47.7 & 18739 \\
\hline Higher & 14.7 & 5783 \\
\hline \multicolumn{3}{|l|}{ Education of women } \\
\hline No education & 37.9 & 14866 \\
\hline Primary & 15.3 & 6018 \\
\hline Secondary & 37.7 & 14793 \\
\hline Higher & 9.1 & 3579 \\
\hline \multicolumn{3}{|l|}{ Religion } \\
\hline Hindu & 75.2 & 29525 \\
\hline Muslim & 11.8 & 4642 \\
\hline Christian & 8.6 & 3361 \\
\hline Others & 4.4 & 1729 \\
\hline \multicolumn{3}{|l|}{ Caste } \\
\hline Scheduled caste & 17.2 & 6744 \\
\hline Scheduled tribe & 12.2 & 4777 \\
\hline Other backward caste & 36.3 & 14241 \\
\hline Others & 31.2 & 12237 \\
\hline \multicolumn{3}{|l|}{ Wealth index } \\
\hline Poorest & 11.5 & 4526 \\
\hline Poorer & 15.5 & 6101 \\
\hline Middle & 20.2 & 7925 \\
\hline Richer & 24.4 & 9565 \\
\hline Richest & 28.4 & 11140 \\
\hline \multicolumn{3}{|l|}{ Regions } \\
\hline North & 11.0 & 4321 \\
\hline Central & 21.5 & 8433 \\
\hline East & 9.3 & 3641 \\
\hline Northeast & 16.0 & 6299 \\
\hline West & 14.8 & 5802 \\
\hline South & 27.4 & 10761 \\
\hline
\end{tabular}

highly educated ( 26 percent out of 50 percent) in the first and third marriage cohort ( 38 percent out of 62 percent).

The pattern of educational homogamy by socioeconomic status and marriage cohort is presented in Table 5. Educational homogamy showed an increase for all religions. Among Hindus, it increased from 50 percent in 1964-84 marriage cohort to 55 percent in 1996-2006. For Muslims and Christians the corresponding increase was from 50 percent and 54 percent, respectively, in 1964-84 cohort to 57 percent and 62 percent, respectively, in 1996-2006. On the other 
TABLE 3: Percentage distribution of educational attainment of the study sample by marriage cohort, India.

\begin{tabular}{|c|c|c|c|c|c|}
\hline Marriage cohort & No education & Primary & Secondary & Higher & Sample size \\
\hline \multicolumn{6}{|c|}{ Education of women } \\
\hline 1964-1984 & 55 & 18 & 24 & 4 & 8201 \\
\hline 1985-1995 & 42 & 16 & 35 & 8 & 15363 \\
\hline 1996-2006 & 25 & 14 & 48 & 13 & 15679 \\
\hline \multicolumn{6}{|l|}{ Education of men } \\
\hline 1964-1984 & 26 & 24 & 41 & 10 & 8201 \\
\hline 1985-1995 & 22 & 20 & 45 & 14 & 15363 \\
\hline 1996-2006 & 14 & 16 & 53 & 18 & 15679 \\
\hline
\end{tabular}

TABLE 4: Educational attainment of couples by marriage cohort and place of residence.

\begin{tabular}{|c|c|c|c|c|c|c|c|}
\hline \multirow{2}{*}{ Marriage cohort } & \multirow{2}{*}{ Place of residence } & \multirow{2}{*}{ Education of women } & \multicolumn{4}{|c|}{ Education of men } & \multirow{2}{*}{ Homogamy } \\
\hline & & & No education & Primary & Secondary & Higher & \\
\hline \multirow{8}{*}{ 1964-1984 } & \multirow{4}{*}{ Urban } & No education & 14.0 & 8.9 & 12 & 1.3 & \multirow{8}{*}{49.7} \\
\hline & & Primary & 1.5 & 4.0 & 10.3 & 1.4 & \\
\hline & & Secondary & 1.1 & 2.8 & 25.9 & 9.7 & \\
\hline & & Higher & 0.0 & 0.0 & 1.3 & 5.8 & \\
\hline & \multirow{4}{*}{ Rural } & No education & 33.6 & 13.5 & 18 & 1.4 & \\
\hline & & Primary & 2.1 & 5.2 & 8.6 & 0.9 & \\
\hline & & Secondary & 0.4 & 1.6 & 11.0 & 2.2 & \\
\hline & & Higher & 0.0 & 0.0 & 0.1 & 0.4 & \\
\hline \multirow{8}{*}{ 1985-1995 } & \multirow{4}{*}{ Urban } & No education & 10.1 & 5.0 & 9.5 & 0.8 & \multirow{7}{*}{55.4} \\
\hline & & Primary & 2.0 & 3.4 & 8.7 & 0.7 & \\
\hline & & Secondary & 1.8 & 4.0 & 30.5 & 9.5 & \\
\hline & & Higher & 0.0 & 0.0 & 2.5 & 11.4 & \\
\hline & \multirow{4}{*}{ Rural } & No education & 28.6 & 10.5 & 16.7 & 0.9 & \\
\hline & & Primary & 3.5 & 4.1 & 7.6 & 0.6 & \\
\hline & & Secondary & 1.4 & 3.0 & 16.6 & 4.5 & \\
\hline & & Higher & 0.0 & 0.0 & 0.7 & 1.3 & 50.6 \\
\hline \multirow{8}{*}{ 1996-2006 } & \multirow{4}{*}{ Urban } & No education & 6.2 & 2.9 & 5.4 & 0.4 & \multirow{7}{*}{62.7} \\
\hline & & Primary & 1.6 & 2.5 & 5.0 & 0.5 & \\
\hline & & Secondary & 2.2 & 4.8 & 38.2 & 9.2 & \\
\hline & & Higher & 0.1 & 0.0 & 5.1 & 15.8 & \\
\hline & \multirow{4}{*}{ Rural } & No education & 16.2 & 7.0 & 12.9 & 0.5 & \\
\hline & & Primary & 2.9 & 4.2 & 8.4 & 0.7 & \\
\hline & & Secondary & 2.4 & 4.1 & 29.1 & 6.9 & \\
\hline & & Higher & 0.0 & 0.1 & 1.4 & 3.1 & 52.6 \\
\hline
\end{tabular}

hand, percentage of hypergamy declined from 45 (44) in 1964-84 cohort to 41 (34) and 36 (23) in 1985-95 and 19962006 cohort, respectively, in rural (urban) areas. Further, in the first two cohorts homogamy was highest among illiterates in Hindu, Muslim, and other religions. In the third cohort, however, homogamy increased among the better educated individuals. Among the Christians pairing between educated individuals was high in all three marriage cohorts.

Among the scheduled castes, homogamy declined from 55 percent in the first marriage cohort to 50 percent in the second. There was a slight increase in homogamy to 51 percent in the third cohort. Among the "other backward classes" and "other" caste category, homogamy increased from 1964-84 to 1996-2006 cohort, whereas there was considerable decline in educational homogamy among the scheduled tribes. Among the caste groups, pairing of uneducated individuals was the highest in the 1964-84 and 1985-95 cohorts irrespective of any caste group (table not shown). In the 1996-2006 cohort, homogamy increased between better educated individuals in all the caste groups.

In the poorest quintile, homogamy declined from 65 percent in 1964-84 marriage cohort to 57 percent in the 19962006 cohort. In contrast, homogamy in the richest quintile increased from 48 percent in 1964-84 marriage cohort to 68 percent in 1996-2006 marriage cohort. Moreover, in the lower quintiles (i.e., poorest, poorer, and middle) homogamy was high among uneducated individuals, whereas in the higher quintiles (i.e., richer and richest) homogamy was high 
TABLE 5: Educational homogamy by marriage cohort (1964-2006) and selected background characteristics of women in India.

\begin{tabular}{|c|c|c|c|c|c|}
\hline \multirow{2}{*}{$\begin{array}{l}\text { Marriage cohort } \\
1996-2006\end{array}$} & \multirow{2}{*}{ Homogamy } & \multirow{2}{*}{ Hypergamy } & \multirow{2}{*}{ Hypogamy } & \multicolumn{2}{|c|}{ Proportion of } \\
\hline & & & & Hypergamy to homogamy & Hypogamy to homogamy \\
\hline \multicolumn{6}{|l|}{ 1964-1984 } \\
\hline \multicolumn{6}{|l|}{ Religion } \\
\hline Hindu & 50 & 45 & 5 & 0.91 & 0.09 \\
\hline Muslim & 50 & 45 & 5 & 0.89 & 0.11 \\
\hline Christian & 54 & 36 & 10 & 0.67 & 0.18 \\
\hline Others & 52 & 44 & 4 & 0.86 & 0.08 \\
\hline \multicolumn{6}{|l|}{ Caste } \\
\hline Scheduled caste & 55 & 42 & 3 & 0.77 & 0.06 \\
\hline Scheduled tribe & 65 & 31 & 4 & 0.48 & 0.06 \\
\hline Other backward classes & 48 & 47 & 5 & 0.97 & 0.1 \\
\hline Others & 46 & 48 & 6 & 1.05 & 0.12 \\
\hline \multicolumn{6}{|l|}{ Wealth quintile } \\
\hline Poorest & 65 & 32 & 3 & 0.5 & 0.04 \\
\hline Poorer & 54 & 41 & 5 & 0.77 & 0.08 \\
\hline Middle & 45 & 49 & 5 & 1.09 & 0.12 \\
\hline Richer & 42 & 53 & 6 & 1.27 & 0.14 \\
\hline Richest & 48 & 47 & 5 & 0.97 & 0.11 \\
\hline \multicolumn{6}{|l|}{ 1985-1995 } \\
\hline \multicolumn{6}{|l|}{ Religion } \\
\hline Hindu & 51 & 41 & 8 & 0.81 & 0.17 \\
\hline Muslim & 57 & 33 & 10 & 0.57 & 0.17 \\
\hline Christian & 57 & 27 & 16 & 0.47 & 0.28 \\
\hline Others & 59 & 31 & 10 & 0.53 & 0.17 \\
\hline \multicolumn{6}{|l|}{ Caste } \\
\hline Scheduled caste & 50 & 41 & 8 & 0.82 & 0.16 \\
\hline Scheduled tribe & 59 & 36 & 5 & 0.61 & 0.08 \\
\hline Other backward classes & 50 & 41 & 9 & 0.83 & 0.18 \\
\hline Others & 54 & 36 & 10 & 0.67 & 0.18 \\
\hline \multicolumn{6}{|l|}{ Wealth quintile } \\
\hline Poorest & 60 & 35 & 5 & 0.58 & 0.08 \\
\hline Poorer & 50 & 42 & 9 & 0.85 & 0.17 \\
\hline Middle & 44 & 46 & 10 & 1.03 & 0.23 \\
\hline Richer & 45 & 43 & 13 & 0.95 & 0.28 \\
\hline Richest & 61 & 32 & 7 & 0.51 & 0.12 \\
\hline \multicolumn{6}{|l|}{ 1996-2006 } \\
\hline \multicolumn{6}{|l|}{ Religion } \\
\hline Hindu & 55 & 34 & 11 & 0.62 & 0.21 \\
\hline Muslim & 57 & 28 & 15 & 0.49 & 0.26 \\
\hline Christian & 63 & 22 & 15 & 0.35 & 0.25 \\
\hline Others & 61 & 28 & 11 & 0.46 & 0.18 \\
\hline \multicolumn{6}{|l|}{ Caste } \\
\hline Scheduled caste & 51 & 38 & 10 & 0.75 & 0.2 \\
\hline Scheduled tribe & 54 & 34 & 11 & 0.63 & 0.2 \\
\hline Other backward classes & 54 & 34 & 12 & 0.63 & 0.22 \\
\hline Others & 61 & 27 & 12 & 0.44 & 0.2 \\
\hline \multicolumn{6}{|l|}{ Wealth quintile } \\
\hline Poorest & 57 & 33 & 10 & 0.58 & 0.17 \\
\hline Poorer & 45 & 41 & 14 & 0.92 & 0.3 \\
\hline Middle & 50 & 36 & 14 & 0.73 & 0.28 \\
\hline Richer & 57 & 33 & 10 & 0.58 & 0.18 \\
\hline Richest & 68 & 22 & 11 & 0.32 & 0.16 \\
\hline
\end{tabular}


TABLE 6: Patterns of marriage by geographic regions NFHS-3 (200506), India.

\begin{tabular}{lcccc}
\hline Regions & Homogamy & Hypergamy & Hypogamy & $\begin{array}{c}\text { Female } \\
\text { literacy }\end{array}$ \\
\hline West & 58 & 32 & 9 & 73 \\
Northeast & 55 & 32 & 13 & 71 \\
South & 56 & 30 & 15 & 68 \\
North & 52 & 41 & 7 & 63 \\
East & 58 & 34 & 8 & 46 \\
Central & 47 & 48 & 6 & 45 \\
\hline
\end{tabular}

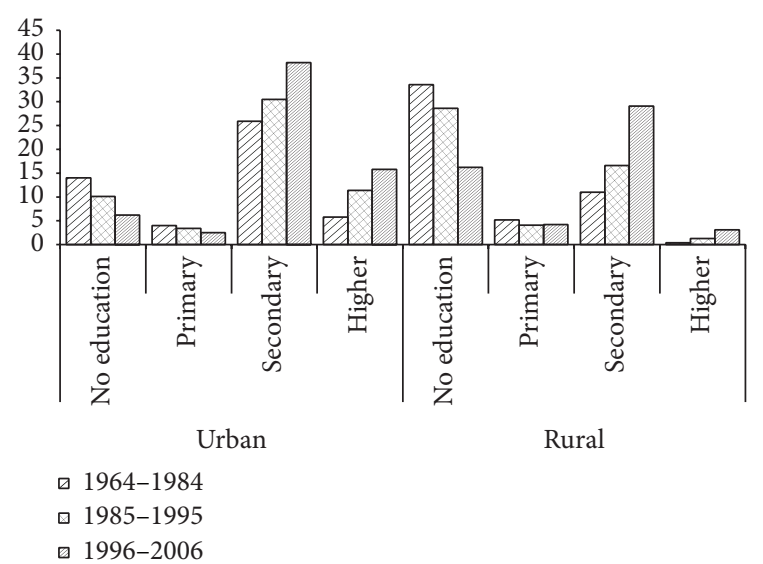

FIGURE 1: Educational homogamy by place of residence and marriage cohort in India.

among educated individuals in all the three marriage cohorts (table not shown).

It was also seen that the increase in homogamy was accompanied by decline in hypergamy and increase in hypogamy in all the categories of religion, caste, and wealth quintiles for the successive marriage cohorts.

The increase in homogamy was not uniform across the different levels of educational attainment. The results show a monotonous decline in homogamy for illiterates and primary educated individuals, in both rural and urban areas (Figure 1). The reverse trend is observed for marriages between better educated individuals (secondary education and above), where homogamy has increased in successive marriage cohorts irrespective of place of residence.

Regional variations in educational homogamy are shown in Table 6 . The regions are arranged in the descending order of female literacy. The percentage of literate female varies from 73 percent in West to 45 percent in the Central region. The results show that the Western region with the highest female literacy has the highest percentage of homogamy followed by Northeastern region. The Central region has the lowest percent of homogamy and the lowest literacy rate.

3.3. Probabilities of Educational Homogamy Obtained from Ordered Logistic Regression. In the next step, the study estimated the probabilities of educational homogamy from ordered logit regression (Table 7). The unadjusted probabilities give the estimates based on education of husband, and adjusted probabilities are the estimates after controlling for other socioeconomic variables. The results show that the unadjusted probabilities are $0.469,0.198,0.663$, and 0.557 , respectively, for uneducated and primary, secondary, and higher educated women. After controlling for the socioeconomic factors and marriage cohort, the probabilities of homogamy change to $0.461,0.205,0.661$, and 0.589 , respectively, with increase in educational attainment of women. Moreover, the probabilities of hypergamy declined after controlling for socioeconomic factors.

\section{Discussion}

Researchers in the field of demography and family studies have long been studying the mate selection process, the factors associated with the process, and the pattern of change over time. Study of marriage and family formation in India largely focused on the similarities in race, ethnicity, religion, and economic condition of the individuals. Besides these factors, education plays a significant role in mate selection. However, educational homogamy remains a relatively less explored and understood dimension in marriage, particularly in the developing countries [27]. Research carried out in developed countries shows that educational homogamy is a growing phenomenon in mate selection $[28,29]$. This is of particular relevance for a culturally diverse country like India where, with rising female literacy levels, mate selection is no longer a matter of parental choice alone. Therefore, this study examined changes in educational homogamy in India using the three marriage cohorts that spanned from 1964 to 2006.

The study observed that the changes in the process of mate selection were characterised by a rapid increase in educational homogamy in the marriage cohorts. A plausible explanation is that the several years of schooling and the resulting exposure to a wider learning environment may influence an individual's choice of partner. Earlier studies also observed an increase in educational homogamy, in India and other developed countries [2, 12-15, 30,31]. Longer time in educational institutions may also increase the probability of finding partners of their choice, that is, of the same educational level. Previous research also suggested that increase in years of schooling increases the chance to meet people with similar educational attainments at the onset of marriageable age [8]. It is also reported that, with increase in female literacy and labor force participation, parents give more importance to the desires and expectation of their children in mate selection, particularly their daughters [32].

This study also found that the increase in homogamy was not uniform for different levels of educational attainment. Homogamy is more common at the extremes of educational attainment. Similar observations were made in an earlier study about changes in educational attainment of couples [18]. It may be inferred that, as a result of an increase in female literacy in India, homogamy has shifted towards the higher end of educational attainment in the successive marriage cohorts. This finding holds for all religion, caste, 
TABLE 7: Probabilities of educational homogamy obtained from ordered logistic regression, NFHS-3 (2005-06), India.

\begin{tabular}{|c|c|c|c|c|c|c|c|c|}
\hline \multirow{3}{*}{ Education of wife } & \multicolumn{8}{|c|}{ Education of husband } \\
\hline & \multicolumn{4}{|c|}{ Unadjusted probabilities } & \multicolumn{4}{|c|}{ Adjusted probabilities } \\
\hline & No education & Primary & Secondary & Higher & No education & Primary & Secondary & Higher \\
\hline No education & 0.469 & 0.248 & 0.269 & 0.015 & 0.461 & 0.245 & 0.282 & 0.013 \\
\hline Primary & 0.167 & 0.198 & 0.575 & 0.061 & 0.176 & 0.205 & 0.564 & 0.055 \\
\hline Secondary & 0.044 & 0.072 & 0.663 & 0.222 & 0.044 & 0.077 & 0.661 & 0.218 \\
\hline Higher & 0.010 & 0.019 & 0.415 & 0.557 & 0.007 & 0.014 & 0.391 & 0.589 \\
\hline
\end{tabular}

and economic condition. As a consequence of the shift in educational homogamy towards higher educated couples, inequity in socioeconomic development of the families may increase in future $[12,33]$.

The patterns of change in educational homogamy differ significantly by place of residence. In urban areas, homogamy is high among better educated individuals whereas, in rural areas, homogamy is high between illiterate individuals. Additionally, the rate of increase in homogamy is higher in urban area than rural areas. It was also seen that, as homogamy increased, hypergamy declined and hypogamy increased in the successive marriage cohorts. This phenomenon may be a consequence of the increase in educational attainment of women. With increase in the levels of female education, they are more likely to marry someone with similar levels of education.

Certain determinants of marriage like caste and religion are inherent. Others like place of residence and economic status may change with time. The study found significant regional variations in educational homogamy. The region with high levels of literacy has high educational homogamy and vice versa. The states with the regions differ in terms of the levels of literacy. The Eastern region has states with the lowest literacy rate in India (Bihar and Jharkhand). The Northeastern region has the state with second highest literacy rate in India (i.e., Mizoram). In the Southern region, Kerala has the highest literacy and two other states, that is, Tamil Nadu and Karnataka, have literacy rates above the national average.

The results also showed that education is the most important factor in mate selection, since the probabilities of homogamy did not change much after controlling for socioeconomic condition of the household. Previous studies also support that women marrying someone with higher education is declining and conversely, the proportion of women marrying down is rising [34]. It is possible that, with improvement in educational attainment, women give more importance to the educational attainment of their prospective partners than other attributes (ethnicity, caste, etc.). Similar thought was put forward by an earlier study that increase in education of women increases the chances of finding men with similar level of education [9]. For illiterate women, better economic condition of the household, living in a developed area, and religious affiliation may be more important than the educational attainment of the prospective partner. Similar research conducted in South Asian countries suggested that in Japan women from recent birth cohorts are more likely to get married if they are highly educated [35].

\section{Conclusion}

The study rejects the hypothesis and concludes that marriage pattern has changed in India over time, with significant increase in educational homogamy for individuals with high education. In urban areas, homogamy is concentrated among the higher educated individuals whereas, in rural areas, homogamy is high among uneducated individuals. This shows that female literacy had a definite role in changing the patterns of educational homogamy. At the same time, the increase in educational homogamy may have a negative influence on the socioeconomic condition of the families and their offspring. Regional variations in educational homogamy were also identified. The region with highest female literacy had the highest level educational homogamy. The region with lowest female literacy had low homogamy but a higher percentage of hypergamy. Therefore, it may be concluded that female literacy is the most important determinant of change in marriage patterns in India.

\section{Competing Interests}

The authors declare that there are no competing interests regarding the publication of this paper.

\section{References}

[1] M. Kalmijn, "Intermarriage and homogamy: causes, patterns, trends," Annual Review of Sociology, vol. 24, pp. 395-421, 1998.

[2] C. R. Schwartz and R. D. Mare, "Trends in educational assortative marriage from 1940 to 2003," Demography, vol. 42, no. 4, pp. 621-646, 2005.

[3] J. Smits, "Social closure among the higher educated: trends in educational homogamy in 55 countries," Social Science Research, vol. 32, no. 2, pp. 251-277, 2003.

[4] G. W. Jones and K. Ramdas, Eds., (Un)Tying the Knot: Ideal and Reality in Asian Marriage, Asia Research Institute, Singapore, 2004.

[5] A. J. Utomo, "Marrying up? Trends in age and education gaps among married couples in Indonesia," Journal of Family Issues, vol. 35, no. 12, pp. 1683-1706, 2014.

[6] G. S. Becker, "A theory of marriage: part I," Journal of Political Economy, vol. 81, no. 4, pp. 813-846, 1973. 
[7] G. S. Becker, "A theory of marriage: part II," Journal of Political Economy, vol. 82, no. 2, pp. S11-S26, 1974.

[8] G. Becker, A Treatise on the Family, Harvard University Press, Cambridge, UK, 1981.

[9] A. M. Basu, "Women's education, marriage, and fertility in south Asia: do men really not matter?" in Critical Perspectives on Schooling and Fertility in the Developing World, C. H. Bledsoe, J. B. Casterline, J. A. Johnson-Kuhn, and J. G. Haaga, Eds., pp. 267-286, National Academy Press, Washington, DC, USA, 1999.

[10] H. P. Blossfeld and A. Timm, Eds., Who Marries Whom? Educational Systems as Marriage Markets in Modern Societies, vol. 12, Kluwer Academic, Dordrecht, Netherlands, 2003.

[11] M. Kalmijn, "Shifting boundaries: trends in religious and educational homogamy," American Sociological Review, vol. 56, no. 6, pp. 786-800, 1991.

[12] R. D. Mare, "Five decades of educational assortative mating," American Sociological Review, vol. 56, no. 1, pp. 15-32, 1991.

[13] Z. Qian, "Changes in assortative mating: the impact of age and education, 1970-1990," Demography, vol. 35, no. 3, pp. 279-292, 1998.

[14] Z. Qian and S. H. Preston, "Changes in American marriage, 1971-1987: availability and forces of attraction by age and education," American Sociological Review, vol. 58, pp. 482-495, 1993.

[15] J. Smits, W. Ultee, and J. Lammers, "Educational homogamy in 65 countries: an explanation of differences in openness using country-level explanatory variables," American Sociological Review, vol. 63, no. 2, pp. 264-285, 1998.

[16] W. C. Ultee and R. Luijkx, "Educational heterogamy and fatherto-son occupational mobility in 23 industrial nations: general societal openness or compensatory strategies of reproduction?" European Sociological Review, vol. 6, no. 2, pp. 125-149, 1990.

[17] G. E. Birkelund and J. Heldal, "Who marries whom? Educational homogamy in Norway," Demographic Research, vol. 8, pp. 1-30, 2003.

[18] A. Esteve and C. Cortina, "Changes in educational assortative mating in contemporary Spain," Demographic Research, vol. 14, no. 17, pp. 405-428, 2006.

[19] B. Goswami, "An investigation into the pattern of delayed marriage in India," Working Paper 275, The Institute for Social and Economic Change, Bangalore, India, 2012.

[20] Brim, "Marital relations," in Marriage in India, V. N. K. Reddy, Ed., Academic Press, Hyderabad, India, 1968.

[21] Z. Rubin, Liking and Loving: An Invitation to Social Psychology, Holt, Rinehart and Winston, New York, NY, USA, 1973.

[22] J. Quilodrán, “Transitions to sexual, marital and reproductive life in Latin America. An analysis of its generational sequences and variations," in Proceedings of the 25th Conference of International Union for the Scientific Study of Population (IUSSP '05), Tours, France, July 2005.

[23] C. Lloyd, Growing Up Global: The Changing Transition to Adulthood in Developing Countries, The National Academies Press, Washington, DC, USA, 2005.

[24] L. Coppola, "Education and union formation as simultaneous processes in Italy and Spain," European Journal of Population, vol. 20, no. 3, pp. 219-250, 2004.

[25] R. Prakash and A. Singh, "Who marries whom? changing mate selection preferences in urban india and emerging implications on social institutions," Population Research and Policy Review, vol. 33, no. 2, pp. 205-227, 2014.
[26] A. Sautmann, Partner Search and Demographics: The Marriage Squeeze in India, http://ssrn.com/abstract $=1915158$.

[27] G. Buze, "New evidence on the causes of educational homogamy," Working Paper 10-18, Department of Economics, Aarhus School of Business/School of Economics and Management, Aarhus University, 2010.

[28] M. Kremer, "How much does sorting increase inequality?" The Quarterly Journal of Economics, vol. 112, no. 1, pp. 115-139, 1997.

[29] R. Fernández, N. Guner, and J. Knowles, "Love and money: a theoretical and empirical analysis of household sorting and inequality," The Quarterly Journal of Economics, vol. 120, no. 1, pp. 273-344, 2005.

[30] S. Dalmia and P. G. Lawrence, "An empirical analysis of assortative mating in India and the U.S.," International Advances in Economic Research, vol. 7, no. 4, pp. 443-458, 2001.

[31] F. Hou and M. John, "The changing role of education in the marriage market: assortative marriage in Canada and the United States since the 1970s," in Analytical Studies Branch Research Paper Series, 2007.

[32] P. Chowdhury, Contentious Marriages, Eloping Couples: Gender, Caste and Patriarchy in Northern India, Oxford University Press, New Delhi, India, 2007.

[33] E. Epstein and R. Guttman, "Mate selection in man: evidence, theory, and outcome," Social Biology, vol. 31, no. 3-4, pp. 243278, 1984.

[34] A. Esteve, J. García-Román, and I. Permanyer, “The gender-gap reversal in education and its effect on union formation: the end of hypergamy?" Population and Development Review, vol. 38, no. 3, pp. 535-546, 2012.

[35] W.-J. J. Yeung and C. Alipio, "Transitioning to adulthood in Asia: school, work, and family life," The ANNALS of the American Academy of Political and Social Science, vol. 646, no. 1, pp. 6-27, 2013. 


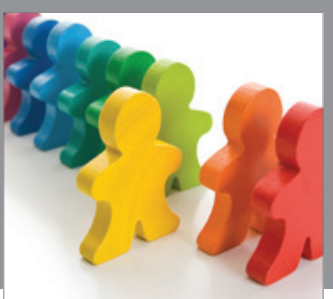

Autism

Research and Treatment
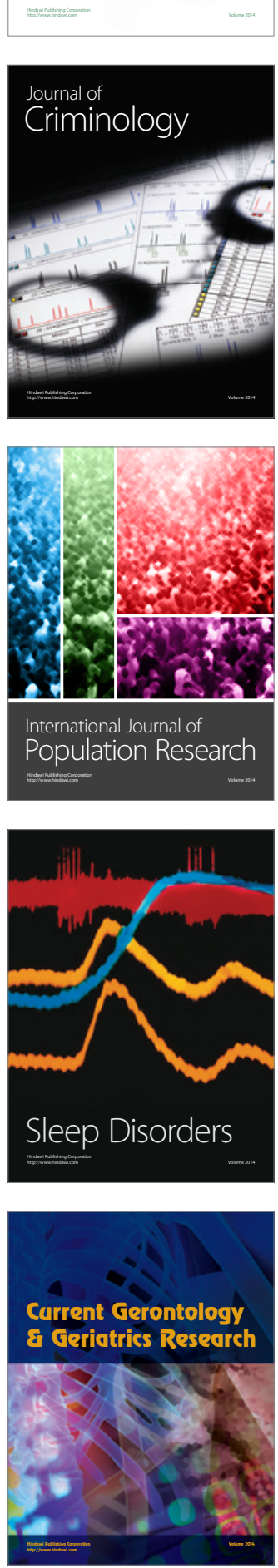

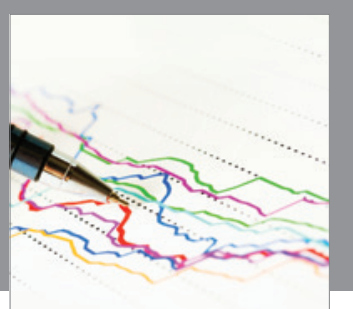

Economics

Research International
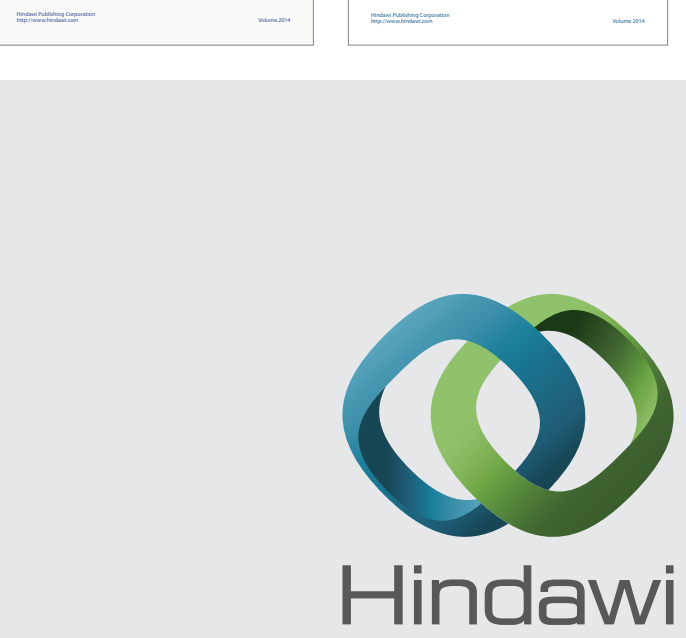

Submit your manuscripts at

http://www.hindawi.com
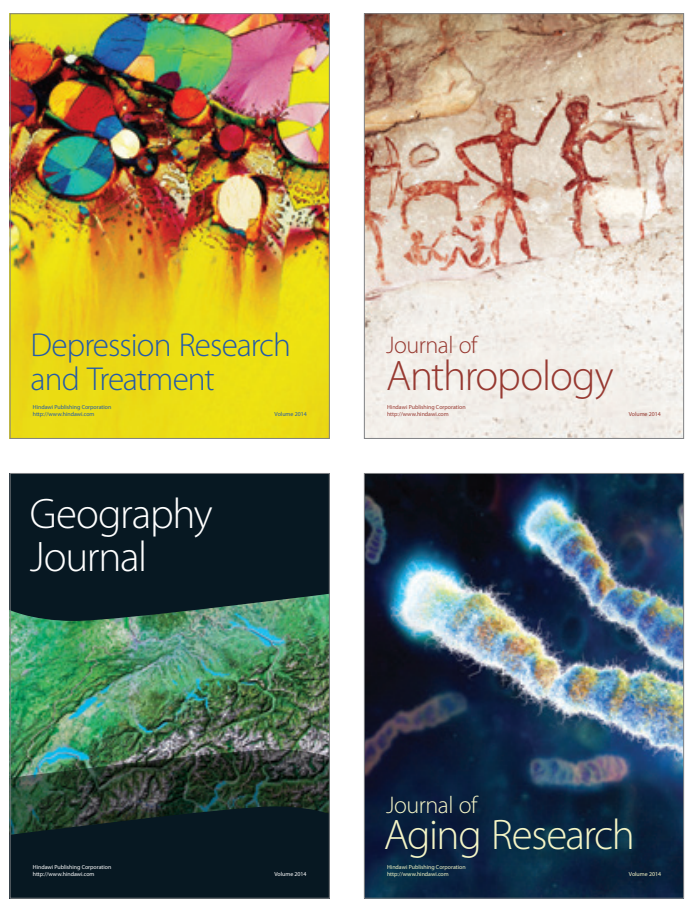
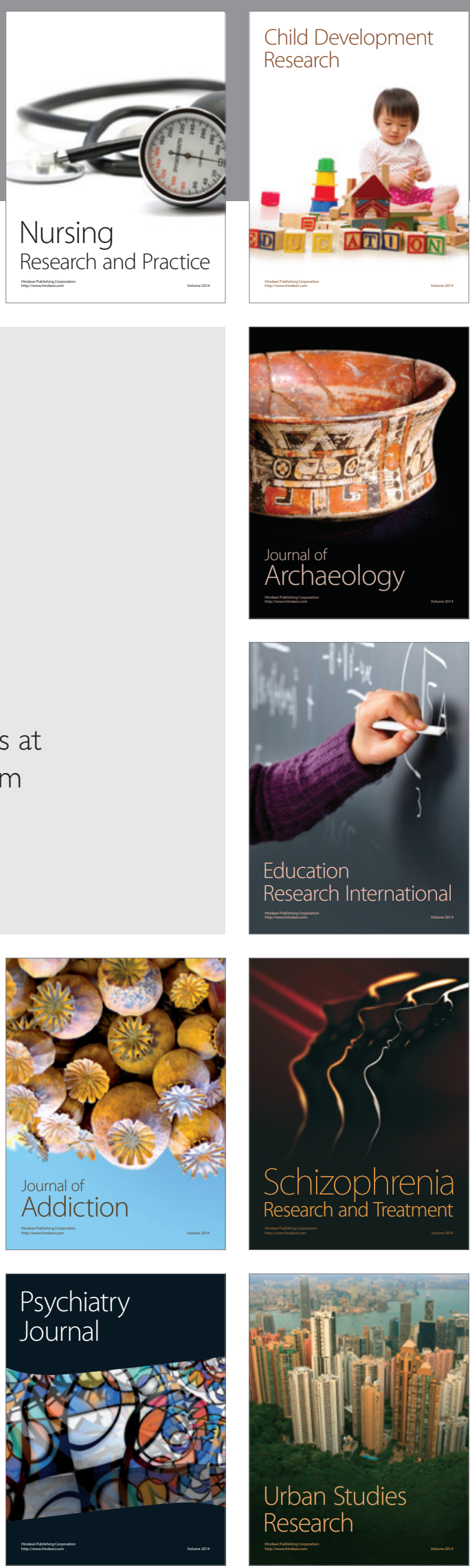